\title{
Bone densitometry at a district general hospital: evaluation of service by doctors and patients
}

\author{
Rajan Madhok, Philip Kirby, John Fordham, Paul Stamp, Sandra Green, Cyrus Cooper
}

Public Health Directorate, Tees Health Joint Administration Middlesbrough Rajan Madhok, consultant in public health medicine Sandra Green, statistician

Department of Public Health Medicine, North Yorkshire Health Authority Philip Kirby, registrar in public health medicine

Department of

Rheumatology, South Cleveland Hospital, Middlesbrough John Fordham, consultant

rheumatologist Paul Stamp, research assistant

MRC Environmental Epidemiology Unit, Southampton

Cyrus Cooper, MRC senior scientist

Correspondence to: Dr Rajan Madhok, Director of Public Health, South of Tyne Health Commission, Horsley Hill Road, South Shields, NE33 3BN

Accepted for publication 28 November 1995

\begin{abstract}
Objective-To assess doctors' and patients' views about a district general hospital bone densitometry service and to examine existing practice to influence future provision.
\end{abstract}

Design-Three postal surveys: $(a)$ of doctors potentially using the service, $(b)$ of patients undergoing a bone densitometry test during a six month period, and $(c)$ of the referring doctors of the patients undergoing the test.

Setting-Bone densitometry service at South Cleveland Hospital, Middlesbrough and two district health authorities: South Tees and Northallerton.

Subjects-All general practitioners $(n=201)$ and hospital consultants in general medicine, rheumatology, obstetrics and gynaecology, orthopaedics, radiotherapy and oncology, haematology, and radiology $(n=61)$; all patients undergoing an initial bone densitometry test $(n=309)$ during a six month period; and their referring doctors.

Main measures-Service awareness and use, knowledge of clinical indications, test results, influence of test results on patient management, satisfaction with the service and its future provision.

Results-The overall response rates for the three surveys were $87 \%, 70 \%$, and $61 \%$. There was a high awareness of the service among doctors and patients; $219(84 \%)$ doctors were aware and 155 of them $(71 \%)$ had used it, and patients often $(40 \%)$ suggested the test to their doctor. The test was used for a range of reasons including screening although the general use was consistent with current guidelines. Two hundred $(65 \%)$ bone densitometry measurements were normal, $71(23 \%)$ were low normal, and $38(12 \%)$ were low. Although doctors reported that management of patients had been influenced by the test results, the algorithm for decision making was unclear. Patients and doctors were satisfied with the service and most $(n=146,68 \%)$ doctors wanted referral guidelines for the service.

Conclusions-There was a high awareness of, use of, and satisfaction with the service. Patients were being referred for a range of reasons and $a$ few of these could not be justified, many tests were normal, and clinical decision making was not always influenced by the test result. It is concluded that bone densitometry services should be provided but only for patients whose management will be influenced by test results and subject to guidelines to ensure appropriate use of the technology.

(Quality in Health Care 1996;5:36-43)

Keywords: bone densitometry service; questionnaires.

Low bone density predisposes to fractures with a significant morbidity and mortality. ${ }^{1}$ The early use of interventions which retard bone loss offers scope for preventing future fractures, particularly in cases of established osteoporosis. ${ }^{2-4}$ The use of bone densitometry in targeting such interventions, however, is contentious. $^{5-7}$ Although it is widely accepted that population-wide bone density screening to target postmenopausal hormone replacement therapy (HRT) is inappropriate, ${ }^{5}$ consensus is growing on the use of the technology in a core of well defined clinical situations in which management may be influenced by the test results. ${ }^{78}$ This view has recently been reinforced by data showing bone density measurements to be effective in predicting future risk of fractures. ${ }^{9-14}$

A bone densitometry service was set up at South Cleveland Hospital in Middlesbrough in February 1991. The service uses a Lunar DPX bone densitometer to measure bone density by dual energy $\mathrm{x}$ ray absorptiometry. Before the scan a "bone health questionnaire" leading to appropriate advice on lifestyle and risk factors for osteoporosis is given. The lumbar spine and both femoral necks are scanned and the results, in $\mathrm{g} / \mathrm{cm}^{2}$, are compared with age and sex specific norms. ${ }^{15}$ The $Z$ scores are computed for the spine and both hips and values below the threshold in any of the three sites are used as cut offs. (Bone density values are usually expressed in relation to reference data as SD scores; the $Z$ score represents the number of SDs above or below the age and sex matched mean reference value.)

The results are sent to the referring doctor: general practitioners (GPs) and hospital doctors, with recommendations on future action as follows: (a) values greater than $1 \mathrm{SD}$ below the mean are within the normal range and no further action is required; $(b)$ values between 1 and 2 SDs below the mean are in the low normal range and the clinician is advised to repeat the scan after 12-18 months, and $(c)$ values lying more than 2 SDs below 
the mean are low results; and the patient is advised to attend the bone clinic conducted by the consultant rheumatologist for full assessment to exclude secondary osteoporosis and to give advice on management (unless the referring clinician requests otherwise).

Increasing demand for the service during 1992 caused concern to the two main purchasing authorities who questioned its value. These authorities were the South Tees Health District where in 1991 the population was 286000 and Northallerton Health District where in 1991 the population was 121000 . The centre of Northallerton is about 15 miles south of South Cleveland Hospital, which is towards the west of South Tees Health District. The Purchasers' concern was also prompted by the first Effective Health Care Bulletin, ${ }^{5}$ which examined the issue of bone densitometry in osteoporosis and advised against its use for population screening.

The purchasers wanted to know whether the continued provision of the bone densitometry service was justified and, if it was, what contract volumes were necessary to meet the need and how should the service be provided: by open access to all doctors or by restricted access? It was acknowledged that it was difficult to answer the main concern because of the difficulty in proving that bone densitometry measurement prevented future fractures, because obtaining such data requires long term studies. On the other hand, it was difficult to stop the service as osteoporosis is a major public health problem and the subject has been covered extensively in the popular media, leading to demands from the public for services relating to osteoporosis.

The study objectives were to ascertain doctors' and patients' awareness, use of, and satisfaction with the service; to determine whether patient management changed as a result of the test; and to obtain doctors' views on how the service might be provided in the future. The results of the study were intended for use by the two local purchasers and the provider in discussions about the future need

\section{National Health Service (NHS) purchasers and providers}

- The NHS reforms in the UK introduced the purchaser-provider split to create an internal market in health care

- Purchasing of health care is undertaken by purchasing authorities (health districts) and general practitioner fundholders

- Purchasing authorities are charged with assessing the health needs of their local population and agreeing contracts for services with hospital and community health services (providers)

- Purchasers thus have the means and mandate to purchase services for their local population that are effective and for which there is demonstrated need

- Patients are registered with local general practitioners (GPs) who are largely responsible for initial patient assessment and (where necessary) referral to specialist inpatient and outpatient services (such as bone densitometry) for and provision of the bone densitometry service (box). We think that this was a pragmatic approach to evaluating a service which is partly driven by patients and partly by doctors and for which the evidence of effectiveness may be incomplete.

\section{Methods}

Three surveys were undertaken: (a) a survey of all doctors potentially using the service; $(b)$ a prospective survey of all patients undergoing a test over a six month period; and $(c)$ a further survey of the referring doctors of all the patients in (b).

\section{FIRST SURVEY (APPENDIX 1)}

The study population consisted of GPs and hospital consultants. The GPs were identified from registers of the Cleveland and North Yorkshire Family Health Service Authorities. Hospital consultants in the following specialties were considered to be potential users: general medicine, rheumatology, obstetrics and gynaecology, orthopaedics, radiotherapy and oncology, haematology, and radiology.

A self administered postal questionnaire was sent to all subjects. Questions were asked about their awareness and use of the bone densitometry service, clinical indications for referral, satisfaction with the service, views on the necessity of the test, and how such a service should be provided. The questionnaire was tested on doctors who were not part of the study. The first posting was in May 1993, reminders were sent to the non-responders after four weeks.

SECOND SURVEY (APPENDIX 2)

All patients resident in South Tees or Northallerton who underwent an initial bone densitometry measurement (patients having a repeat test were excluded) during a six month period, from April to September 1993, were the study population. Four weeks after the test a postal questionnaire was sent to eligible patients to ascertain their understanding of the test result, what advice and medication had been prescribed, their intention of following the drug regimen, and how the referral was initiated. Patients were asked to wait until they had seen a doctor to discuss the test results, or wait at least 10 weeks, before completing and returning the ques-tionnaire; reminders were sent to the nonresponders after 10 weeks. The questionnaire was tested on colleagues who were not part of the study.

THIRD SURVEY (APPENDIX 3)

The referring physicians of all patients undergoing a test in the second survey were the study population for this postal questionnaire survey. For each patient, their referring physician was asked how the test results influenced management. The physicians were asked to wait until they had discussed the test result with the patient before completing the questionnaires; reminders were sent to nonresponders after 10 weeks. 
ADDITIONAL DATA

Personal and demographic details and test results of patients were obtained from the records held at the bone densitometry service.

DATA PROCESSING AND ANALYSIS

Data were entered on a computerised database (DBase IV), with a double data entry procedure to ensure accuracy. For the patients who underwent the tests in the second survey, data from their referring physicians in the first and third survey were collated by merging data files. Ten patients in the second survey were referred by consultants from specialties of general surgery $(n=1)$, occupational health $(n=7)$, urology $(n=1)$, and accident and emergency $(n=1)$. As these specialties were not included in the first survey, these patients were excluded from the analysis. The data were analysed through DBase IV and SPSS/pc+ packages. Subgroup analyses were undertaken between GPs and consultants, and the patients in the two districts. The $\chi^{2}$ test and Fisher's exact tests were undertaken. As there were few significant differences the results are pooled in the tables, with significant results mentioned in the text; a $\mathbf{P}$ value of $<0.05$ was considered to be significant.

Ethics committee approval was given. ${ }^{16}$

\section{Results}

RESPONSE RATES

Altogether there were 201 GPs and 61 consultants in the study. Of these 143 GPs and 44 consultants were in South Tees and 58 GPs and 17 consultants were in Northallerton and the overall response rate for the first survey

Table 1 Results of the first survey: awareness, use of, and views on access to the bone densitometry $(B D)$ service $(n(\%))$

\begin{tabular}{lcc}
\hline & $\begin{array}{c}G P s \\
(n=201)\end{array}$ & $\begin{array}{c}\text { Consultants } \\
(n=61)\end{array}$ \\
\hline Responded & $180(90)$ & $47(77)$ \\
Aware of BD service & $174(97)$ & $45(96)$ \\
If aware; ever used BD service & $131(75)$ & $24(53)$ \\
If ever used the service was it used last year (1992-3) & $125(95)$ & $23(96)$ \\
How should the service be accessed: & & \\
Open access to GPs & $48(27)$ & $3(6)$ \\
Subject to locally agreed guidelines & $121(67)$ & $25(53)$ \\
Restricted to formal referral by a consultant & $6(3)$ & $13(28)$ \\
\hline
\end{tabular}

^Asked of all respondents, five GPs and six consultants did not respond.

Table 2 Usual indications ${ }^{\star}$ and indications with resources constraints in the NHS + for use of the bone densitometry service $(n(\%))$

\begin{tabular}{|c|c|c|c|c|}
\hline \multirow[t]{2}{*}{ Indication } & \multicolumn{2}{|c|}{ Indications from $G P s$} & \multicolumn{2}{|c|}{ Indications from consultants } \\
\hline & $\begin{array}{c}\text { Usual } \\
n=131\end{array}$ & $\begin{array}{l}\text { With constraints } \\
\quad n=179 \ddagger\end{array}$ & $\begin{array}{l}\text { Usual } \\
n=24\end{array}$ & $\begin{array}{l}\text { With constraints } \\
\quad n=46 \ddagger\end{array}$ \\
\hline $\begin{array}{l}1 \text { Because patients ask for it } \\
2 \text { Population based screening of } \\
\text { asymptomatic women }\end{array}$ & $\begin{array}{l}73(56) \\
9(7)\end{array}$ & $\begin{array}{l}31(17) \\
29(16)\end{array}$ & $\begin{array}{c}4(17) \\
0\end{array}$ & $\begin{array}{l}7(15) \\
6(13)\end{array}$ \\
\hline $\begin{array}{l}3 \text { Selective testing of high risk patients } \\
\text { (premature menopause, on steroids, } \\
\text { or family history) }\end{array}$ & $119(91)$ & $165(92)$ & 19(79) & $40(87)$ \\
\hline $\begin{array}{l}4 \text { To help decide whether to prescribe } \\
\text { HRT to women }\end{array}$ & $64(49)$ & $67(37)$ & $8(33)$ & $20(43)$ \\
\hline $\begin{array}{l}5 \text { To monitor patients' response to } \\
\text { treatment for osteoporosis }\end{array}$ & $45(34)$ & $103(58)$ & $6(25)$ & $31(67)$ \\
\hline $\begin{array}{l}6 \text { Diagnostic use in patients with } \\
\text { symptoms suggestive of osteoporosis } \\
\text { (back pain, height loss) }\end{array}$ & $100(76)$ & $142(79)$ & $17(71)$ & $36(78)$ \\
\hline 7 Other & $4(3)$ & $4(2)$ & 0 & $1(2)$ \\
\hline
\end{tabular}

${ }^{\star}$ Only asked of those doctors who reported having used the bone densitometry service; †Asked of all doctors; $\neq$ One missing value. was $87 \%$ (table 1 ). In the second survey, 309 patients received an initial bone densitometry test and 217 completed questionnaires were received (response rate $70 \%$ ). Questionnaires from the third survey were returned by 103 doctors who had referred 188 patients (response rate $61 \%$ ). Complete data from the second and third surveys and the records at the bone densitometry service were available for $137(44 \%)$ patients.

TEST RESULTS

Two hundred $(65 \%)$ bone densitometry measurements were normal, $71(23 \%)$ were low normal and $38(12 \%)$ were low results.

AWARENESS, USE OF, SATISFACTION WITH, AND VIEWS ON THE FUTURE OF THE BONE DENSITOMETRY SERVICE

Doctors' perspectives

There was high awareness and use of the bone densitometry service (table 1); detailed analysis showed that the use was higher in South Tees than in Northallerton and this may be a reflection of the distance between Northallerton and the service. Thus $22(50 \%)$ of the 44 GPs in Northallerton who were aware of the service had used it compared with 109 of $130(84 \%)$ in South Tees $\left(\chi^{2} 18.45\right.$, $P<0.0001)$, and two out of $12(17 \%)$ consultants in Northallerton had used it compared with 22 out of $33(67 \%)$ in South Tees $\left(\chi^{2}\right.$ $6.94, P=0.0084)$. Most of the GPs ( $n=121$, $67 \%)$ and over half of the consultants $(n=25$, $53 \%$ ) wanted the service to be provided through locally agreed guidelines; 13(28\%) consultants suggested access through a formal referral from a consultant.

Table 2 shows doctors' indications for referrals to the bone densitometry service. There were some significant differences between GPs and consultants. For example, more GPs than consultants referred because patients asked for the test $(73 / 131(56 \%) v$ $\left.4 / 24(17 \%), \chi^{2} 10.82, P=0.0010\right)$ and some doctors thought it to be appropriate for population based screening. Apart from four doctors who were not sure the rest of the doctors who used the service were either satisfied or highly satisfied with the bone densitometry service.

\section{Patients' perspectives}

Three hundred and nine patients underwent a bone densitometry test during the study period; their mean (SD, range) age was $57(9.95,16-87)$ years and $298(96 \%)$ were women. The following section applies to the $217(70 \%)$ patients who completed a questionnaire in the second survey.

One hundred and fifty nine $(73 \%)$ patients were aware of the bone densitometry test before they were referred for it and their sources of information about the test included popular media $(116(53 \%))$, friends and family $(67(31 \%))$, and professionals $(32(15 \%))$. Eighty six $(40 \%)$ patients themselves had suggested that they be referred for a bone densitometry test whereas it was suggested by the doctor for $117(54 \%)$ patients. 
Patients' understanding of the results did not always correlate with the real results, and some patients did not understand the result. For example, of the 137 patients with normal test results $122(89 \%)$ patients reported that their bones were normal, six (4\%) thought that their bones were weak, and nine (7\%) did not understand their results. Apart from 14 patients $(7 \%)$ the rest did not experience any discomfort during the test itself and overall, the patients expressed high satisfaction with the service. We asked patients whether they were worried or reassured as a result of the test; table 3 shows their answers along with the test results.

CHANGES MADE TO PATIENTS' MANAGEMENT AS A RESULT OF THE BONE DENSITOMETRY TEST

Doctors' perspectives

The test result influenced the management of $136(72 \%)$ of the 188 patients for whom a questionnaire was returned by the doctor in the third survey. The management of $26(14 \%)$ patients was not influenced by the test, and for 25 patients $(13 \%)$ the doctor was not sure. Many doctors responded to our request for comments on this issue; the following are some examples of written comments along with the doctor's response to whether the result affected management decisions, shown as yes or no in parentheses.

"Confirmed osteoporosis in a patient on long term steroids for chest complaints. Didronel commenced" (yes); "Did not need further investigation or treatment" (yes); "Continuation of HRT not needed" (yes); "Excluded osteoporosis after wrist fracture" (yes); "Reassurance" (yes); "Saved patient from unnecessary medication" (yes); "She had already decided she did not want HRT. She is unable/ unwilling to modify her lifestyle" (no); and "I had to chase the result. Patient attended to ask for it and I had not received it. She has not returned - it is normal" (no).

The advice given to patients included no further action $(n=105,56 \%)$, medication prescription ( $n=44,23 \%)$, repeat test $(n=31$, $16 \%)$, and modification of lifestyle $(n=27$, $14 \%)$.

\section{Patients' perspectives}

Table 4 shows the type of advice given according to the test results of the 97 patients who reported receiving advice. Many patients with normal results reported being given

Table 3 Reassurance or worry of patients due to the test results $\left(n=211^{\star}\right)$

\begin{tabular}{lccc}
\hline $\begin{array}{l}\text { Patient's response } \\
(n(\%))\end{array}$ & \multicolumn{3}{c}{ Test result $(n(\%))$} \\
\cline { 2 - 4 } & $\begin{array}{c}\text { Normal } \\
(n=139)\end{array}$ & $\begin{array}{c}\text { Low normal } \\
(n=51)\end{array}$ & $\begin{array}{c}\text { Low } \\
(n=21)\end{array}$ \\
\hline Very reassured (64(30)) & $52(37)$ & $10(20)$ & $2(10)$ \\
Reassured $(92(44))$ & $62(45)$ & $24(47)$ & $6(29)$ \\
No different (39(18)) & $23(17)$ & $10(20)$ & $6(29)$ \\
Worried (14(7)) & $1(1)$ & $7(14)$ & $6(29)$ \\
Very worried (2(1)) & $1(1)$ & 0 & $1(5)$ \\
\hline *Six patients did not respond; their results were normal $=3$,
\end{tabular}

$\star$ Six patients did not respond
low normal $=1$, low $=2$. various medications and advice on lifestyle. Of the patients receiving medication, most $(90 \%)$ thought that they were more likely to take their prescribed medication as a result of the test but many were not sure how long they would need to continue medication. For example, 10 of the 25 patients on HRT did not know how long they would need to have it and four thought that they were required to take the medication for less than five years.

The responses from doctors were checked against those of the patients for whom all such data were available and showed some mismatch. For example, of the 13 patients for whom their doctor reportedly had prescribed HRT, only 10 patients reported receiving such a prescription. Similarly, 13 doctors reported advising calcium but only nine patients recalled this.

\section{Discussion}

Our study confirmed that there was a high awareness of and demand for the bone densitometry service and that there was a high level of satisfaction with the service. We acknowledge the limitation of ascertaining satisfaction in this way but there were few written criticisms from either doctors or patients. A large proportion of doctors surveyed were using the service, and patients often themselves suggested the test to their doctors. Although most doctors used bone densitometry for valid indications $^{7}$ some were using it because patients asked for it and for population based screening. In the first case we are uncertain whether patients' demands were the sole reason for testing or whether it was performed as part of the total decision making process based on clinical history, examination, and counselling. It was surprising to note that $16 \%$ of doctors would have advocated the test as part of a population screening programme even when resources were constrained. This conflicts with the recommendations of the Effective Health Care Bulletin and points to a need for wider education of physicians. An alternative explanation may lie with the media campaigns on osteoporosis which were ongoing at the time of the study.

Table 4 Advice given as a result of the test, as reported by the patients (only asked of those patients who reported that further action was advised $(n(\%))$

\begin{tabular}{|c|c|c|c|c|}
\hline \multirow[t]{2}{*}{ Advice* } & \multicolumn{4}{|c|}{ Test result } \\
\hline & $\begin{array}{l}\text { Normal } \\
(n=41)\end{array}$ & $\begin{array}{l}\text { Low normal } \\
\quad(n=37)\end{array}$ & $\begin{array}{c}\text { Low } \\
(n=19)\end{array}$ & $\begin{array}{c}\text { Total } \\
(n=97)\end{array}$ \\
\hline $\begin{array}{l}\text { Diet } \\
\text { Medication: } t\end{array}$ & $25(61)$ & $25(68)$ & $10(53)$ & $60(62)$ \\
\hline HRT & $8(20)$ & $7(19)$ & $10(53)$ & $25(26)$ \\
\hline Calcium & $4(10)$ & $6(16)$ & $8(42)$ & $18(19)$ \\
\hline Bisphosphonates & $3(7)$ & $5(14)$ & $7(37)$ & $15(15)$ \\
\hline Other drugs & $3(7)$ & $2(5)$ & 0 & $5(50)$ \\
\hline Exercise & $14(34)$ & $14(38)$ & $10(53)$ & $38(39)$ \\
\hline To reduce smoking & $3(7)$ & $6(16)$ & $7(37)$ & $16(16)$ \\
\hline To avoid falls & 0 & $7(19)$ & $6(32)$ & $13(13)$ \\
\hline Other action & $3(7)$ & $5(14)$ & 0 & $8(8)$ \\
\hline $\begin{array}{l}\text { To cut down on } \\
\text { alcohol }\end{array}$ & 0 & $1(3)$ & 0 & $1(1)$ \\
\hline
\end{tabular}


Most doctors reported that the test result had influenced patient management but their subsequent decisions seemed inconsistent with the actual test results in some cases. For example, almost two fifths of patients who did not have a definitive low result were prescribed HRT and almost one quarter were given calcium. We recognise that many patients with a normal bone densitometry measurement may still be prescribed HRT but wonder whether a test should have been undertaken in such circumstances. However, non-oestrogenic interventions such as the bisphosphonates are now being intensively investigated in the primary prevention of osteoporosis, and the role of bone densitometry in targeting them, or monitoring their use, will also need to be considered. ${ }^{17}$ Although it can be argued that a normal test is reassuring to patients and doctors, the scale of it (with overall $65 \%$ of the tests being normal) requires justification in a resource limited service.

Some patients' lack of proper understanding of their bone strength after the test is also relevant. We evaluated the written comments from those patients who indicated that they "did not really understand" their bone strength and found a mixture of problems relating to communication and explanation of results. Some of these are amenable to correction (for example, unclear handwriting on report form), and some reflect complex clinical situations or low normal results. Furthermore, it is possible that some of the advice reported as being given as a result of the test was actually recalled from the time of the test itself, when the bone counsellors gave advice based on the patient's response to a bone health questionnaire given before the test. Finally, there may be a methodological problem in that we asked patients about their understanding of bone strength and not bone density, which is what was actually measured. As bone strength also depends on bone architecture and not just on density, the phrasing of our question may have confused the issue.

The response rate of $87 \%$ for the first survey was particularly gratifying given the fact that doctors are busy professionals who have been "surveyed" extensively on many issues in recent years. Although non-responders may well have different views about the service the fact that $32 \%$ of the responders had never used it suggests that the views of non-users have been represented. Similarly, the responses to the patients' survey and the subsequent survey of the referring doctors were gratifying. We recognise that ultimately we only had complete data for $44 \%$ of the patients but we think that the data from various sources gave valuable perspectives and did not detract from the overall conclusions.

The dual energy $x$ ray absorbtiometry technology has been evaluated and considered to be an accurate and reliable means for measuring bone density. ${ }^{18}$ The best means of reporting and interpreting bone density measurements, on the other hand, remains uncertain. The World Health Organisation (WHO) has recently proposed that osteo- porosis be designated at a bone densitometry value of 2.5 SDs or more below the young normal mean at any site. ${ }^{18}$ Established osteoporosis is defined as a bone density of this level in a patient who has already sustained a low trauma fracture. The cut off values used to define normal, low normal, and low bone densitometry in our study were arbitrary but followed the traditional approach that values of one and two SDs below the normal expected means for a population of that age and sex were abnormal. With these cut off values we found that the yield of the test in terms of low and low normal results was small; overall only $12 \%$ of those tested showed a low bone density. This may be a reflection of the particular clinical cohort that we studied.

The WHO criteria were released after we had completed our study and hence we are unable to recompute our data in line with them, but it would be interesting to examine the yield of the test in future research with the WHO criteria.

There is now a considerable interest in bone densitometry further provoked by the recent publication of the Department of Health report on osteoporosis, ${ }^{8}$ and there will be calls for increased access to bone densitometers.

In summary, our study showed that patients were being referred for a range of reasons (some unjustified, such as screening); many referrals were initiated by patients; often the test result did not influence clinical decision making, although we acknowledge that this part of the study was incomplete because of missing responses and because we do not know what the doctors would have done in the absence of the test; and that some patients did not understand the test results. On the other hand, we could not recommend withdrawal of the service given the disease burden due to osteoporosis and the high demand and satisfaction expressed with it.

Accordingly, it was recommended to the two purchasing authorities that they should continue to purchase the bone densitometry service but subject to guidelines (the favoured option of doctors for accessing the service: table 1) and only for patients whose management would be influenced by test results.

There are, however, still some unresolved issues around the provision of bone densitometry services. What is the most cost effective yield of the bone densitometry test; should it be that $50 \%$ of tests show low density and influence management; in which case what about people who feel reassured as a result of a normal test? What value do we place on such reassurance? Is correct medication prescribed after the test? Will patients comply with advice? Finally, would all patients who could benefit from a bone densitometry test come forward for the test, and in any case how many eligible patients are there in the community? Future research needs to consider such questions alongside the data on fractures.

We are grateful to our GP and consultant colleagues and the patients for participating in the study; and South Tees District Medical Audit Advisory Commitree, particularly Dr J R CoveSmith. We thank North Yorkshire Health Authority for funding the study. 


\section{Appendix 1: Doctors' questionnaire BONE DENSITOMETRY SERVICE STUDY 1993}

(V5.0-12.5.93)

$$
\text { Questionnaire No }
$$

1 Are you aware of the existence of the bone densitometry service at South Cleveland Hospital, Middlesbrough?

Yes

No

(go to question 8)

2 Have you ever used this bone densitometry service?

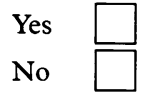

(go to question 8)

3 Can you tell us if you have used this service in the last financial year (April 1992 - March 1993 inclusive)?
Yes
(go to question 5)
No

4 If you have used this service in the past but not during 1992-3 was it because:

There were no suitable patients during 1992-3

You sent patients to a similar service elsewhere

Can you please tell us where:-

\section{Other reason}

Can you please tell us this reason:-

5 Can you tell us what is/are your reason(s) for referring patients to the bone densitometry service? Is it:

i Because patients ask for it

ii Population based screening of asymptomatic women as a means of estimating future fracture risk

iii Selective testing of patients who seem to be at high risk of osteoporosis because of their medical history - for example, premature menopause, steroids, family history, etc

iv To help decide whether or not a perimenopausal woman should go on to HRT or alternative

v As a means of monitoring a patient's response to treatment for osteoporosis

vi Diagnostic use in patients who have symptoms or events suggestive of osteoporosis - for example, fracture from minimal trauma, back pain, loss of height, etc

vii Other reason(s)

Please tell us what other reason(s):-

6 How satisfied are you with the service provided by this bone densitometry service to your patients?

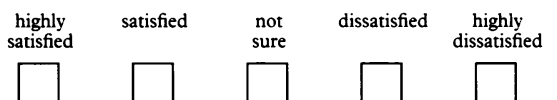

7 If you are not satisfied can you please explain why?

8 Given the resource constraints in the NHS, how necessary do you think a bone densitometry service is for each of the following uses? Please tick one box for each case. $\begin{array}{ll}\text { i } & \text { Because women ask for it } \\ \text { ii } & \begin{array}{l}\text { Screening of } \\ \text { asymptomatic women, to } \\ \text { estimate future fracture }\end{array}\end{array}$ risk

iii Selective testing of patients at high risk of osteoporosis

iv To help decide whether or not a perimenopausal women should go on to HRT (or alternative)

$v$ As a means of monitoring a patient's response to treatment for osteoporosis

vi Diagnostic use in patients with symptoms or events suggestive of osteoporosis

vii Other reason (please state):-

9 If you do think the service is required, how do you think it should be accessed?

Open access to GPs directly

Open access to GPs subject to locally agreed clinical guidelines for referrals

Restricted to formal referral by a hospital consultant

Some other method (please explain):-

If you have any further comments please write here

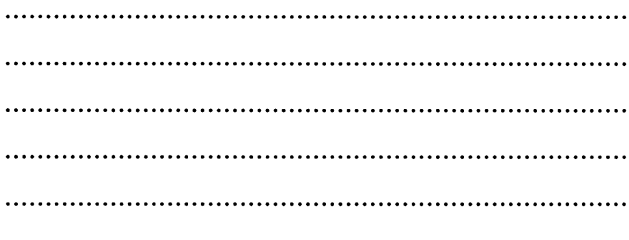

Please tick here if you would like a report.

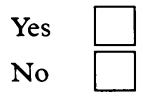

THANK YOU FOR YOUR HELP. PLEASE POST THE COMPLETED FORM IN THE POST-PAID ENVELOPE PROVIDED. 


\section{Appendix 2: Patients' questionnaire BONE DENSITOMETRY SERVICE STUDY 1993}

(V5.0-12.5.93)

\section{Questionnaire No}

1 This test was requested by your GP/a hospital doctor. Has this doctor discussed the test results with you?

$$
\begin{aligned}
& \text { Yes } \square \text { (please go to question 2) } \\
& \text { No }
\end{aligned}
$$

Which doctor did discuss the test results with you?

2 When did the doctor discuss the results of the test you had at South Cleveland hospital? Please write the date here:-

$$
\text { /__ /199 }
$$

Also please note today's date here:

3 Had you ever heard of this type of test from any source before your doctor referred you for it?

$$
\begin{aligned}
& \text { Yes } \square \text { (please go to question 4) } \\
& \text { No } \square \text { (please go to question 5) }
\end{aligned}
$$

4 Where did you first hear about the test? (please tick as many boxes as necessary)

i Popular media (for example, magazines, $T V$, radio)

ii Friends/family

iii Medical source (for example, leaflet, nurse)

iv Other source (please explain):-

5 Who first suggested the possibility of having the bone test?

Did you suggest it to your doctor

Did your doctor suggest it to you

Cannot remember

Other

(please specify who, if other):-

6 As a result of this test, what is your understanding of your bone stength now? Do you think?

Your bones are normal

Your bones are weak

You did not really understand

If you did not understand please try to explain why:-

7 Have you been advised to take any action as a result of your test?

$$
\begin{aligned}
& \text { Yes } \square \text { (please go to question 8) } \\
& \text { No } \square \text { (please go to question 9) }
\end{aligned}
$$

8 If you were given any advice as a result of your test, what was the advice were you given? (please tick as many boxes as needed)

i Take medication

ii Change diet

iii Take more exercise

iv Cut down on smoking

v Reduce alcohol consumption

vi Avoid any falls

vii Take other action

Please explain any other action advised?-

If you have not been advised to take any medication/s for your bones, please go on to question 12

9 If you have been advised to take any medication/s for your bones Can you tell us what the medication/s are. Please write the name/s here:MEDICATION

(1)

(2)

(3)

10 What is your understanding of how long you will have to take the medication/s?

For less than 1 year

For $1-5$ years

For 5-10 years

For life

Note sure

11 Would you say that you are more, or less, likely to agree to take these medications as a result of having had the bone test?

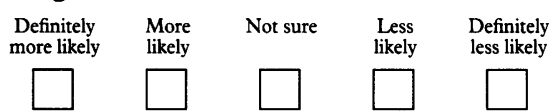

12 How would you describe your experience of having the test? Would you say having the test was:

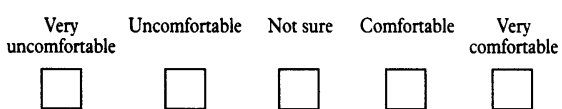

Please write any comments here:-

13 As a result of the bone best do you feel:

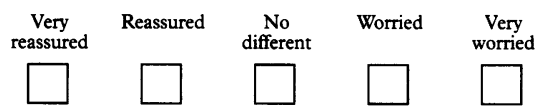

We would be interested in contacting you sometime in the future to learn how you are doing. Would it be alright to contact you again?

Yes

No

THANK YOU FOR YOUR HELP. PLEASE POST THE COMPLETED FORM IN THE STAMPED AND ADDRESSED ENVELOPE PROVIDED. 


\section{Appendix 3: Referring doctors' questionnaire BONE DENSITOMETRY SERVICE STUDY 1993}

(V5.0-12.5.93)

Questionnaire No

This questionnaire pertains to

1 When did you discuss the test results with the patient? Please write this date here:1199

2 Please indicate your reason(s) for referring this patient:

The patient requested it

Population based screening of asymptomatic women as a means of estimating future fracture risk

Screening the patient because he/she appears to be at high risk of osteoporosis because of his/her medical history

To help decide whether or not a perimenopausal woman should go on to HRT or alternative

As a means of monitoring the patient's response to treatment for osteoporosis

To aid diagnosis in a patient with symptoms or events suggestive of osteoporosis

Other reason (please state)

3 What advice did you give to the patient? Did you say that the patient:

Needed no further action

Needed medication now

Needed to modify his/her lifestyle

Needed to have bone densitometry test repeated in the future

Other advice
Please explain any other advice:-

4 If any medication was prescribed can you tell us what it was?

Hormone replacement therapy

Calcium

Other

Please explain what other medication:-

5 If calcium was prescribed, can you tell us what was the daily dose given:-

6 On balance, do you feel that the results of the bone densitometry test influenced the management of this patient in any way?

Yes

Not sure

No

Please could you give details on how the test result affected the management of the patient.

THANK YOU FOR YOUR HELP. PLEASE POST THE COMPLETED FORM IN THE STAMPED AND ADDRESSED ENVELOPE PROVIDED.
1 Consensus Development Conference. Diagnosis, prophylaxis, and treatment of osteoporosis. June 1993. Am $\mathcal{f}$ Med 1993;94:646-50.

2 Ettinger B, Genant HK, Cann CE. Long-term estrogen replacement therapy prevents bone loss and fractures. Ann Intern Med 1985;102:319-24.

3 Naessen T, Persson I, Adami H-O, Bergstrom $R$, Berqvist L. Hormone replacement therapy and the risk for first hip fracture. Ann Intern Med 1990;113:95-103.

4 Cooper C, Aihie A. Osteoporosis: recent advances in pathogenesis and treatment. $Q \mathscr{F M} 1994 ; 84: 203-9$.

5 School of Public Health, University of Leeds; Centre for Health Economics, University of York; Research Unit, Royal College of Physicians; Department of Health Screening for osteoporosis to prevent fractures. Leeds: Leeds University, 1992 (Effective Health Care Bulletin No 1.)

6 Raffle AE. Report on bone mass screening for osteoporosis: a review of reviews. Bristol: Health Care Evaluation Unit, review of reviews. Bristol: Health Care Evaluation Unit, Department of Epidemiology and

7 Johnston CC Jr, Slemenda CW, Melton LJ III. Clinical use of bone densitometry. $N$ Engl f Med 1991;324:1105-9.

8 Barlow DH. Advisory Group on Osteoporosis. London: Department of Health, 1994.

9 Wasnich RD, Ross PD, Heilbrun LK, Vogel JM. Prediction of postmenopausal fracture risk with use of bone mineral measurements. Am f Obstet Gynaecol 1985;153:745-51.

10 Hui SL, Slemenda CW, Johnston CC Jr. Baseline measurement of bone mass predicts fracture in white women Ann Intern Med 1989;111:355-61.
11 Gardsell P, Johnell O, Nilsson B. Predicting fractures in women by using forearm bone densitometry. Calcif Tissue Int $1989 ; 44: 235-42$.

12 Cummings SR, Black DM, Nevitt MC, Browner WS, Cauley JA, Genant HK, et al. Appendicular bone density and age predict hip fracture in women. $\mathscr{F} A M A 1990$ 263:665-8.

13 Melton LJ, Atkinson EJ, O'Fallon WM, Wahner HW, Riggs BL. Long-term fracture risk prediction by bone mineral assessments at various skeletal sites. $\mathcal{F}$ Bone Miner Res 1993;8:1227-33.

14 Cummings SR, Black DM, Nevitt MC, Browner W, Cauley J, Ensrud $\mathrm{K}$, et al. Bone density at various sites for prediction of hip fractures. The Study of Osteoporotic Fractures Research Group. Lancet 1993; 341:72-5.

15 Truscott JG, Oldroyd B, Simpson M, Stewart SP, Westmacott CF, Milner $R$, et al. Variation in lumbar spine and femoral neck bone mineral measured by dual energy $x$ ray absorption: a study of 329 normal women. energy $x$ ray absorption: a st.

16 Madhok R. Audit and research. Lancet 1993;340:1103-4.

17 Black DM, Reiss TF, Nevitt MC, et al. Design of the fracture intervention trial. Osteoporosis Int 1993; fracture intervention

18 World Health Organisation. Assessment of fracture risk and its application to screening for postmenopausal osteoporosis. Geneva: WHO, 1994. (WHO Technical Report Series No 843-121-9.) 